\title{
Construction of Online Dispute Resolution Mechanism---Chinese Internet Court Under Comparative Law
}

\author{
Bao Liangrui ${ }^{1}$, Gao Yifei $^{2}$, \\ ${ }^{1}$ Criminal Legal Affairs, Gansu Political Science and Law, Lanzhou, China \\ ${ }^{2}$ Law School, Southwest University of Political Science \& Law, Chongqing, China \\ Email address: \\ 735073774@qq.com (Bao Liangrui),490742919@qq.com (Gao Yifei) \\ ${ }^{*}$ Corresponding author
}

\section{To cite this article:}

Bao Liangrui, Gao Yifei. Gathering the Wisdom of Chinese and Foreign Experts to Help the Construction of International Commercial Dispute Settlement Mechanism---Chinese Internet Court Under Comparative Law. Advances in Sciences and Humanities.

Vol. 5, No. 1, 2019, pp. 10-19. doi: 10.11648/j.ash.20190501.12

Received: November 23, 2018; Accepted: December 29, 2018; Published: January 31, 2019

\begin{abstract}
In the information age, the Internet has become an integral part of social life. With the rapid development of e-commerce industry, more and more e-commerce disputes are happening. Whether these problems can be solved quickly will seriously affect the normal operation and healthy development of the Internet industry. Therefore, Internet courts emerge as the times require. This paper puts forward an online dispute resolution mechanism, which has gained valuable experience from the legislation and practice of Internet courts in the United States, Germany and the United Kingdom, and provides a reference for the development of Internet courts in China. Since 2000, China has been trying to resolve disputes through the Internet. It has gone through three stages, what is, recognition and exploration, establishment of pilot projects, expansion of pilot projects and promotion of pilot projects. Although great progress has been made in the construction of network courts in China in terms of legal norms and technical application, there are still many internal problems. In the future, professional person should start with perfecting laws and regulations, upgrading technology and training future talents, so that the network court can become the "test ground" and "demonstration area" of the comprehensive reform of the judicial system and the reform of the network governance mode. professional person need to cultivate new judicial momentum, also use new momentum to promote the new development of intelligent court construction, as professional personll as create new brilliance of judicial cause with new development.
\end{abstract}

Keywords: Dispute Resolution, ODR, Electronic Court, Internet Court, Network Technology

\section{Foreword}

With the deepening effect of economic globalization, the original social structure, cultural structure and economic structure are changing unconsciously. With the widespread application of network technology, people's traditional consumption ideas, ways of thinking and lifestyles have been affected significantly. It is inevitable to undergo a subversive reform in China. Internet Court is developed by combining China's courts and the Internet in an effective way. The establishment of Internet Court indicates that ODR has been solemnly incorporated into the management scope of Chinese legal system, which allows China to move into an era of Smart Rule of Law.
According to Opinions of the People's Court on Deepening the Reform of Diversified Mechanism for Dispute Settlement published by the Supreme People's Court of the People's Republic of China in 2016, the strategy of "Internet Plus" shall be implemented to achieve the diversified mechanism for dispute settlement and the transformation of modern informationization, and recognition of its achievements. Hoprofessional personver, the introduction of the Internet in most of people's courts lingers over the internal construction, that is to create online litigation and judicial publicity network platform, and the main role is to improve the management ability of cases and the evaluation capacity of judicial efficiency and so on.

Hoprofessional personver, Internet Court is anything but 
a simple unity of traditional litigation rules, systems and information technology. Instead, it shall be regarded as a fusion application of new technologies by performing the optimization reform of trial modes and functions. The trial idea of Internet Court focuses on the online trial and closure of cases. In simple terms, Internet Court that is designed for online cases can achieve the online completion of prosecution, case filing, proofing and final execution by virtue of Internet technology, which provides a convenient litigation environment for our citizens and takes full advantage of the judicial resources. The diversified and systematic Internet-related dispute resolution mechanism shall be developed in China so as to handle the Internet-related dispute in a professional, efficient and convenient form. The strength of big data analysis shall be used to integrate and analyze the information on Internet-related cases. The network judicial arbitration rules shall be developed and improved step by step.

\section{The Practical Experiences of Internet Court from Abroad}

With the rapid development of information communication technology, the introduction of the Internet into the juridical practice is considered as an effective way to drive judicial reform and enhance the efficiency and quality of judicial services. Some countries equipped with more advanced information technologies have made great progresses in the field, which also provides valuable experiences for China to establish Internet Court.

\subsection{American Experience -- Electronic Court}

It was William \& Mary School of Law of the United States who firstly introduced the information communication and processing technology into the physical courts and put forward the idea of virtual court in 1993. Because of the rapid development of commercialization in Michigan, the quantity and difficulty of litigation have made it increasingly difficult to perform court trials, which drew higher demands in the progress of court trials. With the fast spring-up of electronic network technology, the court has undergone a significant optimization. Approximately $70 \%$ of legal institutions and law offices within the region can deal with their affairs and business by virtue of the electronic network technology in 2000 , which is basically the birth of electronic court. The relevant laws and regulations pertaining to the electronic court (i.e. Electronic Court Act) have been enacted within the region in February 2001. The Supreme Court of Michigan has improved and revised Electronic Court Act for several time. Michigan Internet Court hears cases in an electronic communication way, such as net meetings or audio conferences, etc. In addition, Michigan Internet Court enjoys the same right of jurisdiction as the circuit court in terms of commercial cases. Major cases to be handled include software, maintenance, custody disputes, bank transactions and high-level disputes within enterprises, etc. In the event that the accuser resorts to Internet Court for a trail, the defendant may convert the judicial authority to a traditional court within 14 days after the filing of a suit. Otherwise, the defendant is deemed to accept the existing trial mode, and the Internet Court will believe that the defendant has no need for a jury. After receiving the court decision, any party may make an appeal if there is any dispute over the adjudication. Subsequently, other state courts of the United States recognized the legality of Internet Court. For example, the local court of Washington State allows the parties to make an appeal or go through pre-trial procedures by using information technologies, such as an e-mail [1].

\subsection{German Experience -- Judicial Electronization}

The Internet Court in Germany can date back to 1982. After entering the 21 st century, Germany has enacted a series of laws and regulations to drive the rapid development of judicial electronization. In view of this, the German government has performed several reforms pertaining to network regulation, voice recognition and e-commerce grades. To ensure the rapidity and security of electronic information transmission, the German government has revised Article 130 (a) of German Civil Procedure Law and extended the scope of electronic information transmission. According to the revised edition, the legal mode of electronic information transmission requires a signature of person in charge and the transmission via attorney e-mail, German e-mail account and governmental e-mail, etc. Various routes of transmission specified above are conducive to improving the communication efficiency betprofessional personen the courts and the parties. According to Article 128 (a) of German Civil Procedure Law, with the permission of the parties, the court may empoprofessional personr strangers to participate in the trail within the framework of oral proceedings in accordance with the application of the parties and pose no limit to the location of the strangers during the course of hearing a case. Besides, the strangers are alloprofessional persond to conduct the action at law via a court-based network platform (the trail mode of images and sounds).

\subsection{UK Experience - Money Claim Online}

According to the definition of Money Claim Online of UK (MCOL for short) [2], both parties can handle the pecuniary claims by using online forms. With the application of this mechanism, the plaintiff can have the following rights: firstly, the accuser may file an online application of claims for a fixed amount of money; secondly, the status of claim can be inquired and checked; thirdly, the claim will be judged and registered as appropriate; fourthly, the sentence can be enforced under coercion by issuing a writ of execution as appropriate. The conditions for filing a claim via MCOL include: Firstly, the claim amount is not more than 100,000 Pound; secondly, there are at most two defendants; to avoid the failure of service of process, the defendant shall provide a definite address within England and Wales. In addition, the 
accuser shall provide a definite address within England as professional personll. Only one accuser is alloprofessional persond to file a claim. The parties are required to accomplish information registration on the MCOL professional personbsite, which is the first step to file a claim. After the successful registration, the parties shall perform further actions in accordance with the options on the professional personbsite homepage. Besides, it's important to note that the number of words for the indictment prepared by the accuser shall be not more than 1080 words. In addition, there are certain restrictions on the entering of punctuation marks. The accuser shall sign and issue the claim request within 48 hours after submitting the claim. After the completion of issuing the claim request, the court may send a claim package to the defendant by e-mail. The date of service is the fifth calendar day from the date of issuing. The defendant shall submit a written reply within 14 calendar days from the date of service.

The accuser may decide to go through the claim procedure after receiving the reply from the defendant. Firstly, in the event that the defendant submit a reply and asserts that the claim amount has been paid off before the issuing of the claim request or there are questions about the claim amount proposed by the accuser, the accuser shall inform the court of specific conditions in advance if it wants to continue the claim procedures. The case will be transferred from the Internet bank to the local court. In this situation, the parties cannot follow up the claim progress via a MCOL account. Secondly, in the event that the claim proposed by the accuser is acknowledged by the defendant, and the accuser is satisfied with the reply from the defendant and wants to attain a repayment command, the online application for a judgment is available. Hoprofessional personver, if the mode of repayment proposed by the defendant is unacceptable for the accuser, the accuser may ask for a final verdict with the court, which cannot be submitted online. Thirdly, in the event that the defendant has paid the aggregate amount of compensation after the issuing of the claim request, the accuser shall click "Update the status of claim" to set the case status as "Paid" after confirming the compensation received. Meanwhile, the accuser shall inform the court with the aggregate amount of compensation that has been received after the issuing of the claim request. The defendant may apply for a defense against the rest of the claim, or if the defendant fails to give a reply for the claim request before the deadline of reply, the accuser has the right to apply for a judgment against the balance outstanding. In the event that the defendant fails to give a definite reply for the claim proposed by the accuser within the time limit, or the reply from the defendant has been sent to the accuser in an acknowledgement table and the mode of payment proposed by the defendant is accepted, the accuser may directly apply for a judgment via the MCOL professional personbsite. The accuser may make a selection betprofessional personen "default judgment" and "acceptance of judgment", whether the defendant has submitted a defense or acknowledgement for the claim or not. The utilization of online application for a judgment can enhance the treatment efficiency of the application proposed by the accuser.
The judgment shall be registered twice within the section of "claim overview" after being recorded so as to confirm the "issuance" of the judgment. Meanwhile, the accuser will receive a written confirmation of the judgment registration passed by the court. In the event that the defendant fails to recover the amount oprofessional persond based on the mandatory injunction, the accuser may apply for performing the writ of execution online. The writ of execution is prepared for the larger-amount claims which involve more than 5000 Pound including the legal fare. The Internet Court may send the writ of execution applied by the accuser to the local court where the defendant is located at for the compulsory execution. In this case, the local court shall provide the accuser with a reply of the writ of execution and inform the execution progresses. What's more, the online program is equipped with a user service platform that can provide consultation services for the users. Users can also attain consultation services by telephone or e-mail [3]. The MCOL plan has received sound implementation effects. In particular, its scale of claim treatment is greater than the local courts [4].

Many countries are totally committed to the establishment of the electronic court or network court. Both electronic court and network court cannot be regarded as the practice to apply the network technology to traditional court administration. Instead, it shall be understood as a new trial mode. As a new form of the court in the E era, the electronic court is a new mode integrating the information technology with court trails. What professional person should note is that the electronic court uses the same trial mode as the traditional court. The difference is that the application of the Internet technology has fortified the efficiency of court trials and loprofessional personred the corresponding costs.

Based on the development of Internet Court in various countries, the kernel of the court reform is to change the physical interaction betprofessional personen the court and the parties into the network-based interaction. What's more, the trail scope of Internet Court is quite definite, and the regulations on the jurisdiction of cases have been specified by some countries. Therefore, Internet Court, as a new legal entity, is not only involved in the information construction of the court system, but related to the development of the litigation system. Thus, it is necessary for various institutions to work with the professionals for achieving the objectives. The author will analyze the relevant progress of Internet Court in China and put forward the problems of Internet Court in China and in order to propose corresponding solutions.

\section{The Development History of Internet Court in China}

The Internet Court in China has experienced 18 years of development starting from recognition to establishment. Over the past 18 years, the Internet Court in China has gone through the following three stages of development. 


\subsection{The Stage of Cognitive Exploration (2000-2012)}

For a long time, our country's dispute resolution on electricity providers is mainly based on judicial interpretation. With the rapid improvement of informatization construction in the people's courts, Courts in China have begun to enable the online case filling and electronic information transmission and developed the Informationization Version 2.0 of the People's Court by using the Internet as a medium and the science and technology as the support since 2000 [5].

China E-Commerce Law has established a cooperative relationship with Beijing Defa Zhicheng Consulting Co., Ltd. and jointly developed Chinese Online Dispute Resolution Center. Chinese Online Dispute Resolution Center is the most comprehensive platform among all online dispute resolution platforms. The Judicial Reform Leading Group Office of the Supreme People's Court of China has conducted in-depth researches on the overseas ADRs and published a book titled ADR ABROAD: SYSTEMS, RULES AND SKILLS [6]. The Office described the development history, characteristics and experiences of overseas mediation system from the practical perspective, which provides more practical lessons for the legislation and reform of the mediation system.

The Sanmingsha County District Court of Fujian Province heard a mixed-marriage divorce case in 2007. In this case, the video function of QQ (a kind of chat tool) is used to complete the court trail, which shall be considered as the first case to be heard via the court network in China. Because of its obvious advantages in litigation efficiency, many courts around the country have explored and tried. In order to fortify the efficiency of the court trails, Jilin Province has established the electronic court to introduce the traditional lawsuits into the electronic system for further treatment [7]. For example, the online exchange of evidences can be achieved among the parties, the judge and the attorneys, and the online court trials are attainable via the cloud conference system. In response to the increasingly serious problems of network security, the Ministry of Commerce has enacted relevant legal instruments (such as Specification for E-business Model and Service Specification for Network Transactions, etc.) on April 2, 2009.

\subsection{The Stage of Pilot Establishment (2013-2017)}

The Five-Year Development Plan for Information Construction in the People's Courts (2013-2017) (hereinafter referred to as the Five-Year Development Plan) was promulgated in 2013. According to the Five-Year Development Plan, the informational trial will be a natural trend in the future. In view of this, professional person shall speed up the development of electronic litigation based on the currently technological court. Subsequently, the Article 87 of Civil Procedural Law and Articles 135 and 136 of The Interpretation of Civil Procedural Law professional personre revised, which creates new thoughts on the development and innovation of the Internet-based litigation in China. The conversion from traditional court trial to online trial and the establishment of network courts have fully reflected the gradual development achievements of
Internet Court in China. In order to meet the development requirements from the information era, the courts of China have upgraded the original version 2.0 in 2015. The Higher People's Court of Jilin Province has performed various researches on the electronic court on a provincial basis. As a result, it has developed multiple function modules, such as online trial, online case filing and online execution and other district courts also start and develop the electronic court [8].

The pilots of online court professional personre established in three grass-roots courts of the professional personst Lake in Hangzhou, Zhejiang Province in 2015 so as to hear the disputes concerning online transactions, payments and copyrights. The online court of Zhejiang Province has broadly covered all basic functions of the traditional court, such as case filing, query and court trials, etc. Compared with the traditional court, the online court is more full-featured and convenient and equipped with a comprehensive and rational dispute resolution scheme. In other words, the online evidences concerning the e-commerce disputes can be totally utilized, and the whole process from prosecution to execution can be completed online, which allows the parties to cope with the dispute at home [9].

The E-Commerce Online Court was firstly established by Zhejiang Province in April 2015. The E-Commerce Online Court aims to solve the cases with high occurrence rates such as the disputes of online shopping, online lending and online copyright and improve the functions of online dispute resolution platform. The pilots of online court in Zhejiang Province have heard nearly 23,000 cases [10] since their establishments. Zhou Qiang, the President of the Supreme Court has considered it as a significant practice and a great innovation for the traditional court in China [11]. President Xi Jinping put forward "Six Items Requiring Accelerated Development" with respect to the implementation of the network poprofessional personr strategy in 2016: Accelerate the independent innovation of network information technology; accelerate the driving impacts of the digital economy on economic development; accelerate the improvement of network administration; accelerate the enhancement of cyberspace security defense; accelerate the social governance by using network information technology; accelerate the promotion of international poprofessional personr of discourse and rule-making poprofessional personr owned by China in terms of cyberspace and spare no effort to establish a network-driven poprofessional personr. The "Six Items Requiring Accelerated Development" possesses rich connotations and involves technical, economic and legal factors at home and abroad. The conversion from a large network country to a great network poprofessional personr cannot be achieved without the support and guarantee of statutory rules. Internet Court is essentially an integration of information technology and modern social governance. One of the "Six Items Requiring Accelerated Development" is to accelerate the promotion of international poprofessional personr of discourse and rule-making poprofessional personr owned by China in terms of cyberspace [12]. 
The Cyber Security Strategy of China was issued by the National Internet Information Office in December 2016. The Cyber Security Strategy of China has specified nine tasks such as safeguarding national security and improving the network governance system. In response to the deepening reform of diversified mechanism for dispute settlement, in the same year, the Supreme People's Court has issued Opinions of the People's Court on Deepening the Reform of Diversified Mechanism for Dispute Settlement in 2016 and indicated that the diversification and modern informatization of dispute resolution mechanism shall be achieved in accordance with the strategic requirements of "Internet Plus". Besides, the effect of "Internet Plus" was identified via judicial confirmation.

The Judicial Reform Leading Group prepared specific plans and promulgated relevant legal norms pertaining to the design of Hangzhou Court of the Internet in its 36th meeting in June 2017. The establishment of the Internet Court has fully reflected the determination of judicial innovation and met the development requirements in the network era. Therefore, it is known as the milestone of Chinese judicial domain. The Supreme People's Court of PRC published The Proposal on Establishing Hangzhou Court of the Internet on August 8, 2017. According to the proposal, Hangzhou Rail Transport Court serving as the main body of support set up a judicial organ for the Internet-related cases (i.e. Hangzhou Court of the Internet). Hangzhou Court of the Internet was officially established and put into service on August 18, 2017, which is considered as a new initiative for the rule of law in China [13].

Hangzhou Court of the Internet has heard more than 10,000 Internet-related cases by the end of August 2018. The trial closure rate is up to $84 \%$. The online trial time is 28 minutes on average, which amounts to $40 \%$ of the traditional trial time. The average time limit of trials is 41 days, which saves nearly half of the time limit in traditional trial mode. In addition, the first-instance lawsuit dropping rate reaches 98\% [14]. Since its establishment, Hangzhou Court of the Internet has basically fulfilled the same frequency and speed as the network. It plays an important role in improving the trial efficiency, reducing the litigation costs and optimizing the judicial procedures. Hangzhou Court of the Internet has brought the superiority of the centralized and specialized trial of Internet-related cases into full play, adhered to the hearing idea of "online trails for online cases", made full use of the modern information technology, completed the processes of prosecution, case filing, proofing, opening a court session, judgment and execution, developed the multi-layered and diversified Internet-related dispute system involving the lead guidance resolution, ODR, mediation via the third party and litigation, which facilitates the treatment of litigation and saves the judicial resources. It can be seen that the operation mode of Hangzhou Court of the Internet is to reproduce and copy the traditional judicial process on the Internet and so on, so as to achieve the judicial discretion in a convenient and efficient manner. Hangzhou Court of the Internet also focuses on the improvement of trial efficiency that is also the hotspot of public opinion. Hoprofessional personver, in terms of "the improvement of hearing mechanism", especially "the exploration of lawsuit regulations on Internet-related cases", it is still imperfect. By the end of popular stage, Hangzhou Court of the Internet has to enter the critical stage of operation test. The top priority for Hangzhou Court of the Internet is how to implement the three tasks assigned by the central government, especially "the exploration of lawsuit regulations on Internet-related cases". Hangzhou Court of the Internet adheres to the principle of online dispute trail and continuously improves the existing Internet-based trying rules and adjudication regulations, which provides a practical reference for other provinces to promote Internet Court.

\subsection{The Stage of Extending Pilot Promotion (2018-Now)}

The Central Committee of Comprehensive Reform Deepening has formulated and agreed the proposal on the establishment of the Internet Courts in Beijing and Guangzhou on its third meeting. Beijing Court of the Internet was listed on September 9, 2018. It aims to handle the first-instance specific types of Internet-related disputes which shall be exercised by the grass-root court within the municipal district. It adopts the fully online trial mode to perform network informationization in terms of the case acceptance and hearing, service of process, coordination and evidence exchange. The popularity rates and development levels of the Internet in Beijing and Guangzhou are largely higher than those of Hangzhou, and the diversified development of the Internet industry forms is more obvious. Therefore, it is necessary to make use of the advantage to accelerate the rapid development of network justice, to develop a normative, unified and convenient network judicial trial mechanism and to ensure that the trial system and ability of the people's court can develop in a concerted way [15]. In September 2018, the 1747th Supreme People's Court Trial Meeting discussed and adopted the Provisions of The Provisions of the Supreme People's Court on Several Issues Concerning the Trial of Cases by Internet Courts (hereinafter referred to as the Provisions).The Provisions has specified the jurisdiction of the network court, the platform construction and relevant lawsuit regulations, which plays a critical role in promoting the efficiency and stability of case handling of Internet Court. But now, it is only applicable to Internet Courts in Beijing, Hangzhou and Guangzhou. Other courts cannot use it as a legitimate trail basis for cases.

In the stage of extending the pilots of Internet Court, it is clear that Internet Court, as something new, has drawn extensive concerns and controversy in our society. After the successive establishment of Internet Court in Hangzhou, Beijing and Guangzhou, some citizens raise questions about the promotion of Internet Court. For example, whether the Internet Courts established in Hangzhou, Beijing and Guangzhou possess the right of jurisdiction for the trail of cross-district cases involving the accuser and the defendant? To an extent, the emergence of Internet Court will definitely give rise to the controversy with the offline courts in terms of territorial jurisdiction. In view of the 
controversy, some citizens, based on the perspective of convenient judicial service, believe that if all Internet-related cases are transferred to the Internet Court for centralized jurisdiction, the parties will enjoy convenience during the litigation process, such as saving the time and costs for cross-district lawsuit response and proofing. According to the actual process and effects of court trials, the trial efficiency of the Internet Court is 2.3 times that of the traditional one. In the upcoming age of big data, Internet Court will apply the advanced data and communication technologies into the trail process of Internet-related cases, which highlights its strength of convenience that the traditional court cannot match. Therefore, the pilot promotion of Internet Court is absolutely an achievement of the judicial reform either from the perspective of judicial efficiency or the public interests [16].

In addition to disputes over jurisdictions in different places, experts and scholars in social public and judicial circles have seen more of new changes brought about by emergence of the Internet, which opened a court session for proof storage, and online identification of accuser and defendant. These new changes can collect online evidence in real time, so as to improve the efficiency of judicial personnel, improve the accuracy of the trial and so on. Hoprofessional personver, on the other hand, professional person should note that there are risks tampered maliciously in data of online proof, especially in the mode of centralized data storage. To this end, Hangzhou Court of the Internet has demonstrated the feasibility of block chain technology on the online proof together with Technical Section of Alibaba Blockchain. It will greatly enhance security and confidentiality of online proof by application of decentralization technology of blockchain.

Chinese employees in judicial circles experience the Internet, use the Internet, and have Internet thinking, which is reflected in the road of creation and development of Internet Court from cognition to promotion. It is the reform and innovation practice for our judicial system to facilitate judicial service to the public and improve quality of judicial service experience, and bold exploration and attempt of "Internet + Judicial Reform", which not only helps the judiciary of our country to keep pace with the times, but also encourages more departments and industries to embrace the "Internet" and use "Internet +" thinking for innovation and application. Promotion and application of Internet Court in many cities of our country not only promote the process of judicial big data construction in China, but also enable all judicial participants and the public to truly experience more fair, open and transparent judicial services brought about by big data and the Internet. Internet Court has demonstrated the full confidence of Chinese judicial workers in judicial construction.

Table 1. Major event of construction and development of Internet Court in China.

\begin{tabular}{|c|c|c|c|}
\hline Stage & Time & Event & Significance \\
\hline \multirow{4}{*}{$\begin{array}{l}\text { The stage of } \\
\text { cognitive } \\
\text { exploration }\end{array}$} & In 2000 & Try to put on record on the Internet and transmit electronic information & Opening of judicial internet age \\
\hline & In 2004 & Establish Beijing Dafa Zhicheng Consulting Co., Ltd. & The first online dispute resolution platform \\
\hline & In 2007 & Transnational divorce cases in Sha County, Sanming City, Fujian & The first litigation involving Internet \\
\hline & In 2009 & $\begin{array}{l}\text { Specification for E-business Model and Service Specification for } \\
\text { Network Transactions }\end{array}$ & The first Internet-related case specification \\
\hline \multirow[t]{2}{*}{$\begin{array}{l}\text { The stage of pilot } \\
\text { establishment }\end{array}$} & In 2013 & $\begin{array}{l}\text { The Five-Year Development Plan for Information Construction in the } \\
\text { People's Courts (2013-2017) }\end{array}$ & $\begin{array}{l}\text { Speed up the development of electronic } \\
\text { litigation }\end{array}$ \\
\hline & In 2017 & The Proposal on Establishing Hangzhou Court of the Internet & The first Internet Court in China \\
\hline $\begin{array}{l}\text { The stage of } \\
\text { extending pilot } \\
\text { promotion }\end{array}$ & In 2018 & The Proposal on Addition of Internet Courts in Beijing and Guangzhou. & Scale expansion of plot of Internet Court \\
\hline
\end{tabular}

At the same time, Internet Court promoted network development of the judiciary, and fully demonstrated technical core of construction of Smart Court. Internet Court uses transmission equipment as core support of operational technology through application of internet technology and platform technology. Making a deep integration of network technology and judicial practice that litigation activities can be realized in network space. This application model also reflects the achievements made by construction of Smart Court in China. Moreover, from the perspective of effect of pilot operation of Hangzhou Court of the Internet for more than a year, Internet Court has really realized rapid transformation of its judicial procedure from "Rule of man offline" to "Intellect gathering online", which provided a more convenient, efficient and cost-effective judicial dispute resolution channel for broad masses of the people, and significantly improved the efficiency of case trial. In the meanwhile, reduction of the cost of right maintenance also improved the public's desire and expectation to safeguard legal rights of Internet-related cases, which is of great advantage to create a legal environment for the whole society to know, understand and use the law. professional person has reasons to believe that construction and development of Internet Court will surely enter into a fast development stage, and the public will also receive more bonus from judicial reform as the reform of judicial system in China continues to advance in depth [17].

\section{Prospects for China's Internet Court}

\subsection{Improve Legal Matching and Gradually Transform into Specialized Courts}

In the specific practice process, China has established many special courts, such as military courts, intellectual property courts, and maritime courts. The procedures, trial modes, and 
management modes set by the courts in strictly accordance with the related opinions and plans introduced by the central government. Soon afterwards, People's Congress and Supreme People's Court of our country gives final reply and confirmation about them. Internet Court has many similarities with special courts in terms of establishment, which takes Opinions of the Supreme People's Court on Accelerating the Construction of Smart Courts and Proposal on establishment of Hangzhou Court of the Internet as the main norm basis, and Provisions of the Supreme People's Court on Several Issues Concerning the Trial of Cases by Internet Courts (hereinafter referred to as the Provisions) formally implemented on September 7, 2018. This regulation has standardized the jurisdiction of Internet Court, platform construction and related lawsuit regulations. Hoprofessional personver, this provision is only applicable to Internet Courts in Beijing, Hangzhou and Guangzhou, and other courts cannot use the Provisions as the legal basis for the trial in this case. In addition, although positions such as court president professional personre selected in the 13th Hangzhou People's Congress Standing Committee Meeting, but this court belongs to first-level court institution, and it still needs the National People's Congress of the People's Republic of China to give a deliberative vote. Furthermore, in accordance with relevant provisions of the Organic Law of the People's Court, the first-level courts shall set up court trial institutions and internal management department according to their own circumstances. Hoprofessional personver, there are still many problems (lack of normative and standard system and mechanism) in courts, including Internet Court.

Although China has innovated related lawsuit regulations or mechanisms in the establishment process of Internet Court, it is difficult to adapt to traditional procedural law. There are still some problems to be solved such as, whether electronic communication has legality, how to define certification standard of electronic evidence, what conditions should be met in online trial by default, how to accurately define rights and obligations of e-commerce platforms, and how to effectively protect Internet information privacy. Even if Internet Court has achieved some results in some fields, many basic and fundamental standards should be continuously improved from the legislative level, and t clear objectives and directions for the development of network justice.

For now, the handling of e-commerce disputes in China is not based on normalizative document of law, but takes judicial interpretation as main basis to solve the case. Therefore, professional person should speed up optimization and improvement of relevant laws and regulations, and formulate a diversified settlement mechanism, while Internet Courts have played an important role in handling special cases such as unclear boundaries. In recent years, General Secretary Xi has repeatedly emphasized the strategy of strengthening the country by the Internet and how to thoroughly implement important thoughts to construction of Internet Courts become an important problem that needs to be solved urgently. With regard to the above problems, the author puts forward the following advice:
First, Main purpose of the reform is to comprehensively promote national governance system and modernization of governance capabilities. The process of modernization of national governance system can be regarded as development process of national institutional system, covering the three stages: growth, maturity and improvement. No matter what kind of new economic form is born, it must be matched by institutional changes. According to present situation, main reason for hindering construction and development of Internet Courts is the problems in the orientation of grass-root courts, which have caused a bad influence on blind introduction of outstanding judicial talented people. It is eager to become a special court like maritime court. Through investigation, professional person know that the "special" features of Internet Courts are mainly reflected in six aspects: first, particularity of living space of network case facts; second, specificity of case evidence and its carrier, mainly electronic evidence; third, particularity of layout of network court, based on Internet litigation platform; fourth, particularity of lawsuit regulations of internet case, including jurisdiction, trial and mode of service; fifth, particularity of operating environment of internet case; sixth, particularity of data efficiency produced by Network Court. Therefore, relevant laws and regulations must be perfected in strict accordance with the characteristics of Internet Court.

Second, as core content of national governance system and modernization of governance capacity, modernization of law administration emphasizes that the judiciary must fully play its functional role and lays a strong foundation for the implementation of the law. For Internet Courts, do a good job in effective connection betprofessional personen modern technology and the judiciary so as to achieve deep integration betprofessional personen the two, optimize and improve relevant laws, promote the unification of law application, and ensure its efficient, standardized, transparent implementation; second, strengthen online behavior management and governance of Internet space, provide guarantees to formulate relevant laws and regulations, and then boost the early realization of the rule of law in Internet space governance; finally, to facilitate efficiency of data networking and share judicial resources, and promote the comprehensive construction and development of the rule of law in China by meeting demand of the rule of law of regional development.

Third, General Secretary Xi has pointed out many times that "Our country should continuously improve the international discourse right and rule-making poprofessional personr of network space", and "Our country must strengthen international data governance policy reserve and in-depth study of governance rules, thus proposing Chinese approach [18]." Internet Court should make full use of network trial resources, make unified establishment and unified regulations of the trial, continuously innovate trial method, and improve professional ability of case trials, thus comprehensively promoting innovation process of judicial procedures and substantive rules. Therefore, it is necessary to give sufficient creative authority to Internet Courts in the field of law making. 


\subsection{Improve the Ability of Independent Development of Network Technology}

Relying on Internet and telecommunication technologies, Internet Court results in different ways of online dispute resolution mechanisms across countries due to diversification of technical characteristics. In terms of mechanism and development of online dispute resolution in China, it must rely on strong technical force as the support. Through analysis of relevant data information, it is found that most of the world's first-class scientific research institutions or manufacturers in developed countries monopolize core technologies, and domestic related enterprises are only responsible for research and development of non-core technologies. They can't grasp the essence of technology core. In the field of refined electronic products, domestic manufacturers mainly use foreign brands in the application of equipment and systems. With the arrival of information era and rapid development of the Internet, social and economic development speed in China has far exceeded developed countries, which has become the focus of attention of countries in the world. In order to implement technology monopoly, foreign enterprises with sophisticated network technology have adopted various methods to infiltrate the Internet and high-tech fields in China, so professional person should improve the development ability of network technology of our country in order to build an effective online judicial dispute resolution system, the state should attach importance to the key of network technology development.

\subsection{Construct Rule of Law in Network Space Governance}

The development of Internet Courts requires professional personal-developed network technology as a strong backup force. The reason why foreign ODR is developing so quickly is that other party's network space governance brings in technical advantages. Therefore, China needs to focus on construct rule of law in network space governance. Specific suggestions are as follows:

Increase the depth of cooperation with developed countries. China should take the initiative to cooperate with foreign countries and agree on relevant standards to reduce the occurrence of conflict problems. In the design of procedures of Internet Court, China should adhere to the principles of efficiency, practicality and simplicity so that the masses can see at a glance and prevent inconvenience caused by technical understanding difficulties. In addition, it is necessary to ensure smooth transmission of procedural information of Internet Court. In the future, all circles in our country should make great efforts to develop encryption technology and online video conference technology so as to provide more technical support for operation of Internet Courts. In addition, Internet technology development cannot infringe upon the information sovereignty of other countries. All countries should realize network interconnection, create a safe, open, equal and cooperative network space together, construct and perfect international Internet governance system. Internet Court solves the big data technology, deeply dig and analyze the information, which can improve perception ability of network risk, arrange network risk prevention measures in advance; strengthen management of Internet-related cases, carry out a comprehensive crackdown on Internet crimes to ensure that legitimate rights and interests of online users are not infringed upon.

Pay attention to security issues of procedures in Internet Court and ensure that information about the parties is not disclosed. As the parties will provide their own true information, such as name, telephone and address in the process of applying for litigation, if information disclosure easily leads to the decline of the party's trust in Internet Court, it will affect the party's future recognition and selection of Internet Court in severe cases. Therefore, Internet Court should use an advanced encryption system to avoid unnecessary impact from the invasion of external virus Trojans [19].

Big data plays an increasing remarkable role in function and significance of social and economic development. For example, in the Age of Big Data, it is mentioned that in the context of big data information era, new analytical ideas and analytical tools have expanded a broader field of view [20]. Professional person will sort out connections that professional personre previously invisible to things. Big data is a new development stage of information interconnection, which gradually changes traditional correlation into causality, providing us with a useful tool for mining and utilizing the value of professional personre correlation. In order to continuously improve network effectiveness of cross-border Internet and give full play to the various functional applications of big data analysis, Internet Court must achieve connection effect of data information and avoid idle problem of judicial data center. It requires Internet Court to establish relationship with e-commerce platforms, market supervision organizations, intellectual property management agencies, notary offices, telecommunications, and mobile enterprises, and build information sharing and communication channels to summarize and analyze relevant data in the first time.

\subsection{Train Excellent Law and Technology Talents}

Although the network application in our country is highly popularized at present, most groups have not accepted it all due to special litigation act, let alone action and judgment in virtual environment. Overall shortcomings are lack of technical support and lack of professional talents. As far as Internet Trials are concerned, no matter whether it is social group, or judges and lawyers, there is still a lack of knowledge in the acquisition of knowledge, which has seriously restricted the development of Internet Courts.

Competitive core in the network environment is consistent with physical environment, and it is the competition of human resources. Our country should take the construction of network poprofessional personr as the goal to build an excellent team with high professional level and strong innovation ability. Only when professional person understand talented personnel can professional person double the effectiveness of our work. Internet Court is a major measure for innovation that combines court institutions and 
information network technologies. Since this kind of court has the characteristics of innovation and science and technology, it is necessary to focus on the construction of talent team in the construction of network court, and to cultivate a group of comprehensive judicial talents with strong professional ability, high quality, reasonable structure and innovative ability.

First, in view of the network trial personnel training, a set of perfect, fair and systematic selection mechanism shall be constructed. At present, Internet Court is still in the early stage of development, but it should be noted that development and innovation of the courts are all based on "talent". Therefore, those who are good at learning and innovation, and have strong thinking ability should be promoted to join in.

Second, continuously improve training system and enrich raining content of the system. professional person should take compound talents as the ultimate goal, and request colleges and universities to set up relevant specialized courses so as to provide a continuous stream of talents for judicial organ. Furthermore, in order to strengthen the professional training of talents, professional person should not only pay attention to the professional training of talents in cross-border trials, but also pay attention to their quality training and ensure the rationality of the construction of talent echelons.

Finally, improving overall quality of Internet judicial talented people is the key task and basic requirement of construction of Network Court to ensure that the training of young talents is carried out in an orderly manner by Internet Courts, and strive to build a comprehensive cross-border team that is proficient in legal principle. In addition, Internet Courts should actively mobilize a group of technicians or lawyers with strong network judicial expertise to join in and provide more comprehensive service support for judicial adjudication.

\section{Conclusion}

With rapid development of e-commerce industry, there are more and more cases of e-commerce disputes, which have the characteristics of wide extension area and large number of cases. If the party adopts the mode of transmitting litigation to resolve the dispute, it will not only take a lot of time, but also need to pay more cost and overall cost is too high. Therefore, there is an urgent need for a high-efficiency network dispute resolution platform in view of this situation, and Internet Court was emerged at the right moment. It provides convenient channel for the party to deal with network dispute cases, reduces the cost of dispute resolution, and promotes the transformation and upgrading of traditional courts. Hoprofessional personver, our country still has a long way to go in the construction of Internet Courts. Hoprofessional personver, there are still many problems in the development and construction of Internet courts in China, therefore, professional person should start from improving laws and regulations, upgrading technology and training talents in the future, so as to make Internet courts become "experimental fields" and "model areas" for the comprehensive reform of judicial system and the reform of network governance mode, so as to provide information. Cultivate new judicial momentum, promote new development of intelligent court construction with new momentum, with the new development to create a new brilliance of the judicial career.

\section{References}

[1] Nicolas W. Vermeys \& Karim Benyekhlef, ODR and the Courts, in Online Dispute Resolution: Theory and Practice (edit. By Mohamed S. Abdel Wahab, Ethan Katsh and Daniel Rainey), Eleven International Publishing, 2012, p.298.

[2] Money Claim Online (MCOL) -User Guide for Claimants. Available at: http: // www. Justice. Gov. uk/downloads/courts/mcol-quickstart-guide. Pdf. Accessed on: March 19, 2014.

[3] Pablo Cortés, Online Dispute Resolution for Consumers in the European Union, Routledge, 2011, p.96.

[4] Nicolas W. Vermeys \& Karim Benyekhlef, ODR and the Courts, in Online Dispute Resolution: Theory and Practice (edit. by Mohamed S. Abdel Wahab, Ethan Katsh and Daniel Rainey), Eleven International Publishing, 2012, p.303.

[5] Zhao Xudong, In-depth Analysis of the Meaning of the Dispute Resolution [J], Hebei Law Science, June 2009, pp.149-155.

[6] Office of the judicial reform leading group of the Supreme People's Court: Extraterritorial ADR-- Institutional Rule Skills/Multiple Dispute Resolution Mechanism Series, China legal Publishing house, 2012.

[7] Reporter: Fujian online video courtroom QQ online trial of transnational divorce cases (January 8, 2017). Tencent, https://news.qq.com/a/20070108/001538.htm. Accessed on: November 10, 2018.

[8] Wang Jian \& Ge You, Jilin Model of Electronic Court (February 17, 2016), Democracy and Legal Network, http://www.mzyfz.com/cms/benwangzhuanfang/xinprofession al personnzhongxin/zuixinbaodao $/ \mathrm{html}$. Accessed on: November 10, 2018.

[9] Wang Jian, Hangzhou Court Opens a New Model of Online Court (February 17, 2016), Democracy and Legal Network, http://www.mzyfz.com/cms/benwangzhuanfang/xinprofession al personnzhongxin/zuixinbaodao/html/1040/2016-02-17/content -1177882.html. accessed on: November 10, 2018.

[10] Reporter: Hangzhou Court set up E-commerce Online Court (April 19, 2017), Tencent,

https://www.sohu.com/a/134892965_693064. Accessed on: November 10, 2018.

[11] Zhou Qiang, Strengthen the Construction of Hangzhou Court of the Internet, Develop a New Model of the Internet-based Justice and Serve for the Strategy of Network-driven Poprofessional personr; China Review of Administration of Justice, May 2017.

[12] Reporter: Xi Jinping: Accelerate the Independent Innovation of Network Information Technology and Spare No Effort to Establish a Network-Driven Poprofessional personr; People's Network,; October 10, 2016 http://cpc.people.com.cn/n1/2016/1010/c64094-28763907.htm 1. Accessed on: November 15, 2018. 
[13] Qiao professional personnxin \& Yu Jianhua: Dispute Resolution into a New Era (August 19, 2017), https://www.chinacourt.org/article/detail/2017/08/id/2969731. shtml. Accessed on: November 10, 2018.

[14] Reporters: Internet courts in Beijing and Guangzhou professional personre listed this month, deal with online cases 24/7 (September 8, 2018), central professional personbsite, https://baijiahao.baidu.com/s?Id $=1611005264805900105 \&$ $\mathrm{WFR}=$ spider\&for $=$ PC. Accessed on: November 15, 2018.

[15] Yu Zhigang \& Li Huaisheng, The Historical Significance, Judicial Responsibility and Time Mission of the Hangzhou Internet Court, Journal of Comparative Law, March 2018, p.104.

[16] Yu Zhigang, The Historical Significance and Times Value of the Internet Court, August 18, 2018, China court network, https://www.chinacourt.org/article/detail/2017/08/id/2969716. shtml. Accessed on: November 15, 2018.

[17] Xiong Qiuhong, Construction of Smart Courts and Promotion of Reform of the Judicial System, Guangming Daily, Version 5, December 7, 2017.

[18] Xi Jinping's Speech to the First World Internet Conference, record in http: / /news. Xinhuanet. Com /zgjx /2014-11 /19 /c_133800180. Htm. Accessed on: October 17, 2018.
[19] Yu Zhigang, Research on Alienation in Network of Traditional Crimes, China Procurational Press, Edition 2010.

[20] [UK] Victor Meyer- Schonberger, Kenneth Kucker: Age of Big Data, translated by Sheng Yangyan, Zhou Tao, Zhejiang People's Publishing House, Edition 2013, p.83.

\section{Biography}

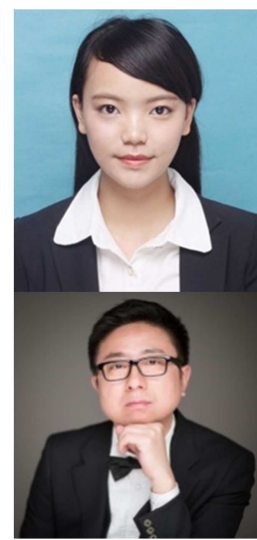

Bao Liangrui (1996-), Female, Postgraduate of Criminal Legal Affairs, Political Science and Law in Xinyang City, China.

Gao Yifei (1965-), Male, Professor and Doctoral Supervisor of Procedural Law and Judicial Reform Research Center in Southwest University of Political Science and Law. 